\title{
Coupled radon, methane and nitrate sensors for large-scale assessment of groundwater discharge and non-point source pollution to coastal waters
}

\author{
Henrieta Dulaiova $^{1 \mathrm{a}}$, Richard Camilli ${ }^{2}$, Paul B. Henderson ${ }^{1}$, and Matthew A. Charette ${ }^{1}$ \\ ${ }^{1}$ Department of Marine Chemistry and Geochemistry, Woods Hole Oceanographic Institution, \\ Woods Hole, MA 02543 \\ ${ }^{2}$ Applied Ocean Physics and Engineering, Woods Hole Oceanographic Institution, Woods Hole, \\ MA 02543
}

\author{
Journal of Environmental Radioactivity \\ Ra-Rn special issue
}

aCorresponding author: hdulaiov@hawaii.edu, current address: Department of Geology and Geophysics, University of Hawaii, Honolulu, HI 96822 


\section{Abstract}

2 We constructed a survey system of radon/methane/nitrate/salinity to find sites of

3 submarine groundwater discharge (SGD) and groundwater nitrate input. We deployed

4 the system in Waquoit Bay and Boston Harbor, MA where we derived SGD rates using a

5 mass balance of radon with methane serving as a fine resolution qualitative indicator of

6 groundwater. In Waquoit Bay we identified several locations of enhanced groundwater

7 discharge, out of which two (Childs and Quashnet Rivers) were studied in more detail.

8 The Childs River was characterized by high nitrate input via groundwater discharge,

9 while the Quashnet River SGD was notable but not a significant source of nitrate. Our

10 radon survey of Boston Harbor revealed several sites with significant SGD, out of these

11 Inner Harbor and parts of Dorchester Bay and Quincy Bay had groundwater fluxes

12 accompanied by significant water column nitrogen concentrations. The survey system

13 has proven effective in revealing areas of SGD and non-point source pollution.

14

15 Keywords: non-point source pollution, submarine groundwater discharge, methane,

16 radon, nitrate, Waquoit Bay, Boston Harbor

17 


\section{Introduction}

19 Recent estimates suggest that groundwater discharge into coastal waters

20 worldwide represents up to one tenth of the total river flow, in some areas it might be as

21 high as one third of the river discharge (Moore, 1996; Dulaiova et al, 2006). Expanding

22 residential and commercial near-shore development is leading to increased nutrient inputs

23 to groundwater that eventually migrate into to coastal waters. Several-decades long

24 research shows that nitrogen inputs via non-point sources over large coastline areas cause

25 decline of ecological health and may support harmful algal blooms (Valiela et al., 1990;

26 1992; Slomp and Van Cappellen, 2004; Lee and Kim, 2007; Umezawa et al., 2008).

27 Current methods to directly measure submarine groundwater discharge (SGD)

28 and corresponding nitrogen fluxes (benthic chambers, seepage meters) are inadequate

29 because groundwater discharge is heterogeneous in location and composition, and occurs

30 over large areas (Burnett et al., 2006). The flow is spatially variable, with water

31 preferentially discharging through conduits in sediments or rocks. Its magnitude is also

32 influenced by temporal variability on tidal and seasonal time scales (Dulaiova et al., 2006,

33 Kim and Hwang, 2002). Marine processes like tides and waves, seasonal declines in

34 hydrologic head in coastal aquifers, and dispersion drive seawater into these aquifers.

35 This water eventually discharges back to the surface creating a second, saline component

36 of submarine groundwater discharge that enhances nutrient transport from the land to the

37 coastal zone (Robinson et al., 2003).

38 Our previous research showed that quantitative estimates of the magnitude of

39 submarine groundwater discharge on a local scale can be obtained from tracer studies

40 (Burnett and Dulaiova, 2003; Burnett et al., 2006). Due to their enrichment in 
41 groundwater relative to surface water, radon and methane serve as universal indicators of

42 both fresh groundwater and recirculated seawater inputs into the coastal zone. Elevated

43 concentrations of these tracers in coastal waters indicate areas where groundwater

44 outcrops to the surface.

45 The utility of ${ }^{222} \mathrm{Rn}$ as a tracer of total SGD has been demonstrated in a wide

46 range of environments from coastal embayments to the coastal ocean (Charette et al.,

47 2008). Rn-222 is a naturally occurring radioactive element with a half-life of 3.8 days.

48 As a non-reactive noble gas its only losses from the water column are due to radioactive

49 decay and evasion to the atmosphere. Because groundwater is in contact with radon

50 emanating aquifer material, ${ }^{222} \mathrm{Rn}$ activities in groundwater are often about two to three

51 orders of magnitude higher than most surface waters. Groundwater becomes enriched in

52 radon independently of its composition (fresh water or seawater) so radon is a tracer of

53 total SGD driven by both terrestrial and marine forces (Dulaiova et al., 2008). If a

54 groundwater source is present in a coastal environment it is likely to be the only radon

55 input of significant magnitude to surface water, which makes this tracer very useful for

56 identifying areas of groundwater input into lakes, rivers and the coastal ocean (Cable et

57 al., 1996; Burnett et al., 2002; Burnett and Dulaiova, 2003).

$58 \quad$ Methane has successfully been employed as a tracer of groundwater inputs into

59 near-shore waters along the coast of the northeastern Gulf of Mexico (Bugna et al., 1996

60 and Cable et al., 1996), Florida Bay (Corbett at al., 2000), Long Island (Dulaiova et al.,

61 2006), and Korea (Kim and Hwang, 2002). Being subject to biological processing,

62 methane is not a conservative tracer though it has proven to be useful where its

63 concentration in groundwater highly exceeds methane inventories in the water column. 
Recent technological advancements have enabled high resolution, continuous

65 measurement of these tracers for large-scale mapping of coastlines. Such measurements

66 using radon monitors have been previously applied (Burnett and Dulaiova, 2003) but

67 only as qualitative surveys to identify SGD hot-spots; none of these studies derived

68 quantitative SGD rates - a major goal of the research described herein. The objectives of

69 our study were to: 1) construct a radon/methane/nitrate mapping system that measures the

70 concentrations of these components in the surface water in-situ with an increased

71 resolution over conventional systems, 2) use tracer data to identify SGD hot-spots and

72 develop a model for its quantitative determination, and 3) assess the importance of SGD

73 with regards to coastal nitrogen budgets and non-point source pollution.

75 2. Methods

76 Our mapping system consists of several component instruments. One of these

77 instruments is a modified radon surveying system (Dulaiova et al., 2005), which consists

78 of 3 commercially available radon-in-air analyzers (RAD7, manufactured by Durridge,

79 Inc., Massachusetts) employed to measure ${ }^{222} \mathrm{Rn}$ from a continuous stream of water

80 passing through an air-water exchanger that distributes radon from the running water to a

81 closed air loop. The exchanger, which takes about 15 minutes to reach full equilibrium in

82 the loop, causes a relatively slow response to changes in radon activities in water. The

83 other disadvantage of the exchanger is that it has a memory-effect due to sluggish

84 flushing of radon from the closed loop. To improve the response time of the system we

85 replaced the air-water exchanger with a membrane contactor (Liquicel, manufactured by

86 Membrana), which is a set of hollow fibers made of a hydrophobic membrane that allow 
87 radon and other gases to pass from water into the air phase. The cell is used as a single-

88 pass open system which has a much shorter memory-effect and requires no wait time for

89 equilibrium. We calibrated the membrane radon stripping efficiency at variable water

90 flow rates though the membrane (1-15 $\left.\mathrm{L} \mathrm{min}^{-1}\right)$ and also by varying the water temperature

91 by heating the water to different temperatures between 5 and $30{ }^{\circ} \mathrm{C}$. For these tests we

92 used groundwater sampled from a well containing $300 \mathrm{dpm} \mathrm{L} \mathrm{L}^{-1}$ radon. We constructed

93 calibration curves of stripping efficiency against water flow-rate and temperature and

94 these curves were used to calculate field data during the surveys. The water flow-rate

95 through the membrane and water temperature in the field were constantly monitored

96 during the survey. During our surveys in Waquoit Bay we included a $10 \mu \mathrm{m}$ and $1 \mu \mathrm{m}$

97 cartridge filter (Osmonics) upstream of the membrane.

98 Methane was measured using a TETHYS in-situ underwater mass spectrometer

99 that was operated on a towed platform from a small coastal boat, providing real-time data

100 to a top-side computer. The TETHYS instrument is capable of measuring dissolved gases

101 and volatile light hydrocarbons at sub ppb levels, with sampling intervals on the order of

1025 seconds for most gases. This technique has been used for ocean floor methane seep

103 mapping in marine environments (Camilli and Duryea, 2007; Mau et al., 2007). For these

104 investigations the mass spectrometer was equipped with an integrated CTD (model

105 SBE49 FastCAT, SeaBird Electronics Inc., Bellevue, Washington, USA) provided

106 continuous flow sample introduction at a rate of approximately $3 \mathrm{ml} \mathrm{s}^{-1}$, along with

107 external salinity, temperature and pressure data.

108 The towed survey was carried out with the mass spectrometer operating at depths

109 between one and three meters. During the survey deployment over 500 discrete sample 
110 measurements of ion peak heights were recorded at m/z 15 as an indicator of relative

111 methane intensity. In addition to the methane time series data, ion peaks at $\mathrm{m} / \mathrm{z} 17,28,32$,

11240 , and 44 were recorded to identify relative changes in gases corresponding, respectively,

113 to water vapor, di-nitrogen, oxygen, argon and carbon dioxide. The methane ion peak

114 intensity (m/z 15) was then normalized to water vapor intensity $(\mathrm{m} / \mathrm{z} 17)$ in order to

115 generate a temperature normalized methane intensity estimate. Spectral sweeps across

116 the instrument's full mass range (2-200 AMU) were performed at selected sites to

117 identify any potential contributions from anomalous gases or volatile hydrocarbons.

118 The survey system is also complemented by a commercially available automated

119 nutrient analyzer (W. S. Envirotech Ecolab) to measure water column nitrate + nitrite

120 concentrations. Other auxiliary measurements include salinity and temperature, which

121 may aid in identifying the nature of groundwater discharge (fresh meteoric water or

122 recirculated seawater). During the surveys the instrument cluster was positioned on a

123 small coastal vessel. Each instrument had an independent water intake pump located at 1

124 m below the surface. The vessel's track was logged using a Garmin global positioning

125 system in 10 second intervals. Post processing of data involved synchronous merging of

126 TETHYS data, radon, salinity, temperature, and nitrate values with GPS tracklog files.

127 Due to varying latency of the instruments, each parameter was measured in different

128 logging intervals. Radon was usually measured in 5 minute integrated intervals, methane

129 including salinity and temperature every 30 seconds, and nitrate was sampled once every

1306 minutes. Therefore in the final results the radon profile is spatially smoothed in

131 comparison to the methane and salinity data that were sampled in much shorter time

132 increments. 
133 In stationary mode we only deployed the radon, salinity and temperature logging systems.

134 In these studies nutrients samples were hand-collected, filtered and kept frozen until

135 analysis. Concentrations of phosphate, nitrate, ammonium, and silicate in hand-collected

136 samples were measured colorimetrically, using a Lachat nutrient auto-analyzer (Hach,

137 Quickchem@ 8000 Series).

138

139 3. Study sites

140 We deployed the mapping system in Waquoit Bay, MA (Fig. 1), an area with

141 extensive prior hydrological and geochemical SGD data sets. Waquoit Bay is a shallow

142 estuary on the south shoreline of Cape Cod, MA. The geologic deposits on Cape Cod

143 consist of outwash gravel, sand, and silt with occurrences of lacustrine deposits of silts

144 and clays (Cambareri and Eichner, 1998). Waquoit Bay receives groundwater from the

145 Cape Cod aquifer, which is an unconfined aquifer, approximately 100 to $120 \mathrm{~m}$ thick and

146 it is bounded by marine water at its margins and less permeable deposits of till and

147 bedrock below. The bay is located along the southern margin of the Sagamore Lens,

148 which is part of the Cape Cod Aquifer. A significant portion of the freshwater input into

149 Waquoit Bay occurs as submarine groundwater discharge (Valiela et al., 1990; Cambareri

150 and Eichner, 1998; Charette et al., 2001). False color imagery of surface temperatures

151 recorded during September 2002 indicate several locations of groundwater discharge into

152 the bay (Mulligan and Charette, 2006). Zones of high groundwater discharge are known

153 to be present in Childs River and down gradient of bluffs along the head of the bay

154 (Mulligan and Charette, 2006). Seepage meter studies indicate that in this area SGD

155 occurs in a narrow ( $30 \mathrm{~m}$ wide) band (Michael et al., 2005). Radon is more than two 
156 orders of magnitude enriched in fresh and saline groundwater relative to surface water

157 (Dulaiova et al., 2008) and the estimated seepage flux determined by a continuous radon

158 model ranges between 0.6 to $5.6 \mathrm{~m}^{3} \mathrm{~m}^{-1} \mathrm{~d}^{-1}$ (Mulligan and Charette, 2006) and is $5.3 \mathrm{~m}^{3}$

$159 \mathrm{~m}^{-1} \mathrm{~d}^{-1}$ based on a ${ }^{226} \mathrm{Ra}$ box model (Charette et al.,2001). The presence of high SGD

160 enriched in both radon and nitrate makes Waquoit Bay an ideal testing site for the

161 mapping system. Using this information about the spatial distribution of SGD we were

162 able ground-truth the sensitivity and resolution of our instruments.

163 In order to contrast seasonal changes in SGD and nutrient inputs, we deployed the

164 complete system to survey the whole periphery of Waquoit Bay on two occasions

165 (August 2006 and December 2006) and we also did a time series stationary monitoring

166 over a 13-hour period simultaneously in two locations as indicated on Figure 1: in Childs-

167 and Quashnet Rivers (September 2007).

168 Following the Waquoit Bay studies we surveyed Boston Harbor, MA and its

169 estuaries (June 2008). The harbor is relatively shallow with an average depth of

170 approximately $5 \mathrm{~m}$, and is well flushed by strong tides, with an average water residence

171 time of five to seven days (Jiang and Zhou, 2008). Our sampling included a stationary

172 long-term monitoring at the University of Massachusetts, Boston dock near Savin Hill

173 Cove for the period between May 2 and June 4, 2008 (Fig. 1). In these Boston Harbor

174 studies the mass spectrometer was not available and the radon monitor was operated with

175 the traditional air-sea exchanger because the water contained significant amounts of

176 suspended matter that clogged the membrane contactor.

177 Boston Harbor was chosen as a more complex environment to demonstrate that

178 the mapping technique is applicable to both surficial and groundwater nitrogen inputs. 
179 Furthermore, despite of the recent improvements in water quality (relocation of the city's

180 sewage outfall offshore), non-point source pollution from SGD and potential relict sewers

181 or combined sewer overflow (CSO) systems are poorly characterized. Greater

182 understanding of submarine groundwater discharge and its spatial distribution throughout

183 the harbor is useful because of the potential for mobilization of contaminants from the

184 highly contaminated (lead, mercury, silver, anthropogenic organic pollutants) bottom

185 sediments (McGroddy and Farrington, 1995; Stolzenbach and Adams, 1998; Eganhouse

186 and Sherblom, 2001), which are the conduit for SGD. Therefore even small fluxes of

187 SGD may be biogeochemically significant if contaminant concentrations are enhanced in 188 groundwater.

190 4. Results and Discussion

\section{$191 \quad 4.1$ Resolution of tracer surveys}

192 The mapping system provides in-situ estimates of radon and methane

193 concentrations in real-time during mapping. This makes it possible to efficiently identify

194 and focus measurements at sites where SGD is occurring, thereby providing better

195 estimates of tracer distributions and the spatial extent of groundwater discharge. This

196 new system has the advantage of a better spatial resolution due to the high resolution

197 methane sampling (every 30 seconds) and an improved radon mapping system.

198 Ultimately the spatial resolution for each of the system's component technologies is a

199 function of sampling interval and survey velocity.

200 We demonstrated that the continuous radon monitor equipped with the membrane

201 contactor has quicker response and less memory effect than the traditional system, 
202 providing better sensitivity to changes in surface water radon activities (Fig. 2). In

203 laboratory conditions the new Liquicel-RAD7 design minimizes response latency

204 because radon is flushed from the system about 4 times faster than from the air-water

205 exchanger (Fig. 2).

206 Similar results were demonstrated during a field survey in Waquoit Bay where we

207 deployed the two radon measurement systems simultaneously. Figure 3a shows that the

208 system equipped with the membrane responded to radon increases by 5 minutes, and

209 decreases about 15 minutes quicker than the system attached to the air-water exchanger.

210 Despite the Liquicel membrane’s advantages for high-resolution radon sampling, it is

211 disadvantageous in that it requires a much more rigorous calibration of radon stripping

212 efficiency with temperature and water flow-rate than the air-water exchanger.

213 Furthermore, the membrane only works in environments with lower fine particulate

214 concentration. During times of high seasonal productivity the membrane clogs quickly,

215 the water flow is restricted and this results in lower radon stripping efficiency.

217 4.2 SGD rates derived from tracers

218 Unlike radon, methane is a non-conservative gas and its concentration may be

219 influenced by microbial and biochemical processes during which it can be produced or

220 consumed in the sediments and water column. It is therefore only useful in areas where a

221 significant concentration gradient exists between groundwater and surface water, in

222 principle, when there is enough anaerobic organic matter decomposition in the aquifer.

223 Correspondingly, groundwater redox $\mathrm{p} \varepsilon$ measured in the subterranean estuary at the head

224 of Waquoit Bay in June 2004 was 1.4 to 7.5, and methane concentrations were 20 to 300 
$225 \mathrm{nM}$ (Charette and Camilli, unpublished results). The samples were collected across the

226 whole salinity gradient (0 to 27) and methane was found in both fresh and saline

227 groundwaters supporting the assumption that methane is a useful tracer for fresh

228 groundwater and recircuated seawater discharge. We tested the applicability of methane

229 as SGD tracer in Waquoit Bay by measuring water column radon and methane

230 simultaneously. We expected that the tracers would have similar spatial distribution if the

231 source of methane was the same as of radon, i.e. groundwater discharge. Indeed, as

232 demonstrated in Figure 3b that is the case, but with the methane data providing a better

233 spatial resolution than radon due to the more frequent methane sampling rate.

234 Differences between the two tracer patterns are likely due to the different sampling

235 intervals (radon being smoothed out spatially) and the non-conservative nature of

236 methane (biochemical sources and sinks in the water column and sediments). Our results

237 from Waquoit Bay demonstrate that in this environment the two tracers complement each

238 other in that methane enables a very fine spatial resolution and radon provides positive

239 identification of SGD origin, confirming SGD as the source of methane.

240 We next evaluate the usefulness of these tracers in assessing the spatial

241 distribution of SGD. The concentration of radon/methane in the water column will

242 depend on several factors (Fig. 4):

243 1) in-situ production by ingrowth from ${ }^{226} \mathrm{Ra}$, radon's radioactive parent dissolved in

244 water/ biogeochemical reactions; 2) inputs by diffusion, sediment resuspension,

245 bioturbation, or gas ebullition from sediments; 3) input by groundwater discharge; 4)

246 removal by exchange with open ocean water (i.e., dilution with low radon/methane

247 offshore water); 5) removal by evasion from water to the atmosphere; 6) losses by 
248 radioactive decay/biogeochemical reactions. Methane biogeochemical production in the

249 sediments and consequent ebullition and methane oxidation in the water column must be

250 considered as a potential source/sink. Hence, we only use this tracer in this study as a

251 qualitative indicator of SGD.

252 Continuous SGD tracer records (Rn, Ra, methane, Si and many others) show that

253 the highest tracer concentrations in the water column can usually be observed at or

254 around low tides (this study Fig. 5 for BH and Fig. 9 for WB; see also Dulaiova et al.

255 2006; Burnett and Dulaiova, 2003). At flood tide the high-tracer coastal waters are

256 diluted by offshore low tracer water (process 4). Because of this dilution process we

257 observe low tracer concentrations at high tide. This pattern is also driven by a change in

258 the hydraulic gradient in the coastal aquifer in response to the tidal fluctuation that causes

259 lower hydrostatic pressure at low tides resulting in increased seepage and thus higher

260 tracer fluxes. To measure the best representative non-diluted coastal tracer inventories

261 we survey during low and ebbing tide.

262 We convert all radon and salinity measurements from our surveys into SGD

263 fluxes based on the following equations:

$264 Q_{S G D_{t o t}}=\frac{A_{R n_{-} w^{*} V}}{\tau * A_{R n \_}, g w}$,

265 and

$266 Q_{S G D_{\text {fresh }}}=\frac{\left(S_{o}-S_{c W}\right) * V}{\tau * S_{o}}$,

267 where $Q_{S G D_{t o t}}$ and $Q_{S G D_{f r e s h}}$ are total (fresh and saline) and fresh submarine groundwater

268 discharge $\left(\mathrm{m}^{3} \mathrm{~d}^{-1}\right), A_{R n_{\_} c w}$ and $A_{R n_{-} g w}$ are radon activities in the coastal water corrected

269 for non-SGD sources and losses and groundwater $\left(\mathrm{dpm} \mathrm{m}^{-3}\right) . S_{c w}$ and $S_{o}$ are coastal water 
270 and offshore salinity. $\mathrm{V}$ is the volume of the coastal water box that the measurement

271 represents $\left(\mathrm{m}^{3}\right)$ and $\tau$ is the flushing rate of the volume of water considered in the

272 calculation.

273 Based on equation (1) the conversion of surveyed radon activity to groundwater

274 fluxes into the coastal zone may be summarized by the following:

275 1) Radon activity in the coastal water $\left(\mathrm{A}_{\mathrm{cw}}\right)$ : Each radon measurement in

276 the survey in this calculation is considered individually and is a

277 representative of a segment of the coastline. This activity is corrected for

278 the following non-SGD related sources and sinks of radon in the water

279 column:

a. We correct for in-situ production from dissolved ${ }^{226} \mathrm{Ra}$ by calculating excess radon as:

b. The amount of radon diffusing from the bottom sediments can be estimated from an experimentally defined relationship between ${ }^{226} \mathrm{Ra}$ content of sediments and the corresponding measured ${ }^{222} \mathrm{Rn}$ flux by diffusion (Burnett et al., 2003). That empirical relationship was derived from experimental data from several different environments (both marine and fresh), where Radon flux by diffusion $\left(\mathrm{dpm} \mathrm{m}^{-2}\right.$ day $\left.^{-1}\right)=495 \mathrm{x}^{226}$ Ra activity + 
of the average measured radon inventory. We assume the same input for Boston Harbor.

c. Radon that is brought to the coast by incoming tides or upstream locations is eliminated from the radon balance by subtracting offshore or upstream radon activities from in-situ radon. This influence can be minimized or even neglected if the mapping is done at low tide and if the study site is well flushed with low-radon offshore waters at high tide.

d. Radon losses due to radioactive decay are calculated using the coastal water residence time ( $\tau$; defined below). Due to the short

$\mathrm{F}_{\mathrm{atm}}=\mathrm{k}\left(\mathrm{C}_{\mathrm{w}}-\alpha \mathrm{C}_{\mathrm{atm}}\right)$

where $\mathrm{C}_{\mathrm{w}}$ and $\mathrm{C}_{\mathrm{atm}}$ are the radon activities in water and air, respectively; $\alpha$ is Ostwald's solubility coefficient; and $\mathrm{k}$ is the gas transfer velocity, a function of kinematic viscosity, molecular 
2) For each measurement the volume of the coastal water box (V) is calculated from the length of the coastal segment, average water column or mixed layer depth, and the width of the seepage face. The length of the coastal segment is the half distance between the previous and following measurements of the survey and it is variable depending on the boat speed, for the surveys in WB it ranged between 10-300 m and in BH 100-300 m. Since radon is measured as an integrated value over this distance, it truly represents this section of the coastline. The width of the seepage face in Waquoit Bay was $30 \mathrm{~m}$ (Michael et al., 2005) and in the absence of better estimates we assumed the same for Boston Harbor. SGD can also be expressed as discharge per meter of coastline $\left(\mathrm{m}^{3} \mathrm{~m}^{-1} \mathrm{~d}^{-1}\right)$ in which case the volume of the coastal box in Eq. (1) and (2) is divided by the coastline length (half distance from the previous plus half distance from the following measurement).

3) The flushing rate $(\tau)$ of the coastal box is considered one tidal cycle (12.25 hours). This is based on our observation from a time series radon measurement in Boston Harbor (Fig. 5) that at high tide the radon values follow a baseline open bay activities indicating that the coastal box is flushed with every tidal cycle. We assume the same for Waquoit Bay. In case the mixing regime is significantly faster then tidal (i.e. due 
to winds and currents) our SGD estimate will be conservative. For these reasons our assumption of mixing on the tidal time scale is more appropriate for our calculation than using the flushing rate of the whole harbor/bay which may be 5-9 days for Waquoit Bay and 5-7 days Boston Harbor (Jiang and Zhou, 2008), respectively.

4) Groundwater Radon $\left(\mathrm{A}_{\mathrm{gw}}\right)$ : We used a groundwater end-member radon activity that was derived during a concurrent study of the subterranean estuary (STE) at the head of Waquoit Bay (Dulaiova et al., 2008) which was dedicated to the description of radon activity across the whole that fresh groundwater has $120 \pm 40 \mathrm{dpm} \mathrm{L}^{-1}$ radon year round, while the recirculated seawater has $410 \pm 190 \mathrm{dpm} \mathrm{L}^{-1}$. Based on the seasonal

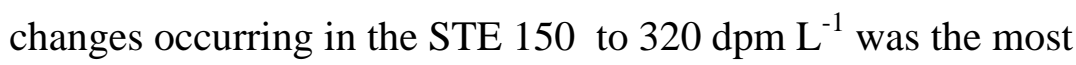
probable groundwater end-member radon activity range for total SGD. We arrived at this value from the expected fresh to saline groundwater ratio in discharging groundwater (Michael et al., 2005). This study has been the most comprehensive in terms of investigation of groundwater end-member activities to date in SGD studies in the literature and includes fresh and brackish to salty groundwater analysis. Hence we are confident that we use the best available radon value in our tracer survey SGD calculations. Still, our assumption here is that there is no large variability in end-member radon activities in the aquifer along the coastline. At study sites where one expects large geological 
heterogeneity, groundwater radon should be measured for each coastal segment in order to lower the uncertainties of the final SGD calculation. One has to consider the benefits of such effort, because an order of magnitude variation in groundwater radon is required to generate an order of magnitude difference in SGD rates.

366 As mentioned earlier we surveyed for SGD tracers at low tide in order to have the least

367 diluted water column by offshore waters during flood tide. At two sites in Waquoit Bay

368 (Childs River and Quashnet River) we tested how the water radon inventory (radon

369 activity $\left[\mathrm{dpm} \mathrm{m}^{-3}\right] \mathrm{x}$ depth[m]) changes over a tidal cycle. Theoretically, if there was no

370 SGD and there were no currents and losses by mixing flood tide should dilute the radon

371 but the water column inventory should stay the same. However, variable SGD, currents

372 and mixing cause fluctuations in radon activity and we found that the radon inventories

373 were 3,000 and $13,000 \mathrm{dpm} \mathrm{m}^{-2}$ at low tide and 4,700 and 8,500 $\mathrm{dpm} \mathrm{m}^{-2}$ at high tide in

374 Quashnet and Childs Rivers respectively. The observed 50\% change in inventories is

375 equivalent to $50 \%$ difference in the calculated SGD. These findings support that the most

376 sensitive survey can be done at low tide when waters are least diluted and least

377 influenced by mixing losses and we expect the highest SGD.

378 Radon provides an estimate of total SGD but it cannot be used to determine the 379 fraction of fresh vs. saline groundwater discharge. In systems with little or no surface 380 runoff it is possible to use salinity and Eq. (2) to calculate fresh SGD. This calculation 381 uses some of the same terms $(\tau, \mathrm{V})$ and is based on similar assumptions as the radon 382 approach described above. Additional assumptions in Eq(2) are that we neglect salinity 383 changes due evaporation and rain. The salinity increasing effect of evaporative distilling 
384 varies due to changes in water temperature, solar radiation, air humidity and wind speed.

385 It potentially influenced the salinity of the surface water in our summer season surveys

386 during which the water temperature was warmer (Waquoit Bay Sep06 average water

387 temperature was $24.5^{\circ} \mathrm{C}$ and Boston Harbor Jul08 average temperature was $17.3^{\circ} \mathrm{C}$ ) than

388 during the winter survey (Waquoit Bay Dec06 average water temperature was $3.8^{\circ} \mathrm{C}$ ).

389 Still, we expect the influence of evaporation to be negligible ( $<0.1$ ppt per tidal cycle;

390 Sumner and Belaineh, 2005) and in the salt balance calculation in Eq(3) we neglect

391 evaporation.

392 Although there are two rivers in Waquoit Bay, they are groundwater fed (Valiela

393 et al., 1990) and we used salinity in this system to calculate a rough estimate of fresh

394 SGD. We could not make the same assumption for Boston Harbor because several rivers

395 and streams deliver significant quantities of freshwater into the harbor. At both sites our

396 SGD estimates also include groundwater delivered to the bay/harbor by gaining streams

397 as these will have higher radon activities and our methods cannot differentiate radon from

398 local and upstream locations.

399 Tracer distributions in Waquoit Bay in Aug 06 and Dec 06 are plotted on Figure

400 6. The bay water was much fresher in Dec 06 than Aug 06 and the corresponding radon

401 and methane levels also suggest higher SGD in the winter. Based on these tracers, the

402 major sources of groundwater are in the Childs and Quashnet Rivers, and at the head of

403 the bay. Methane and salinity provide the best resolution and in some regions they

404 exhibit negative correlation suggesting the presence of fresh groundwater discharge

405 (Childs River). Radon provides assurance that the observed methane profiles are of

406 groundwater origin. As expected, the magnitude of SGD follows the radon and methane 
407 distributions. Using equations (1) and (2) and the corresponding coastline length for 408 each value we derived that maximum SGD rates occur in Childs River $\left(5.5 \mathrm{~m}^{3} \mathrm{~m}^{-1} \mathrm{~d}^{-1}\right.$ of 409 total SGD in summer and some sections as high as $30 \mathrm{~m}^{3} \mathrm{~m}^{-1} \mathrm{~d}^{-1}$ in winter), followed by 410 the head of the bay ( 2 and $3 \mathrm{~m}^{3} \mathrm{~m}^{-1} \mathrm{~d}^{-1}$ in the summer and winter, respectively). We 411 expected elevated SGD in Quashnet River, but due to low water levels we were not able 412 to survey it in such detail as the other parts of the bay. Total SGD fluxes for the whole 413 bay based on radon groundwater activities of $120-310 \mathrm{dpm} \mathrm{L}^{-1}$ are $5.5-11 \times 10^{3} \mathrm{~m}^{3} \mathrm{~d}^{-1}$ in 414 the summer and $28-56 \times 10^{3} \mathrm{~m}^{3} \mathrm{~d}^{-1}$ in winter. From that, fresh SGD rates are 415 approximately $5 \times 10^{3} \mathrm{~m}^{3} \mathrm{~d}^{-1}$ in the summer and $8 \times 10^{3} \mathrm{~m}^{3} \mathrm{~d}^{-1}$ in winter, again these 416 estimates are skewed by the presence of surface runoff. Our calculation of total SGD 417 may also carry an uncertainty related to the change of flushing rate of the near-shore 418 zones for the two different seasons ( $\tau$ in Eq. (1) and (2)).

419 There have been several SGD studies in Waquoit Bay (Mulligan and Charette, 420 2006; Michael et al., 2003; Michael, 2004; Cambareri and Eichner, 1998) with which we 421 can compare our results (Table 1). Our estimates for fresh (920 (Aug 06) and 2050 (Dec $42206) \mathrm{m}^{3} \mathrm{~d}^{-1}$ ) and total (2845 and $4292 \mathrm{~m}^{3} \mathrm{~d}^{-1}$ ) SGD for the head of the bay agreed very 423 well with all previous studies (950 to $2419 \mathrm{~m}^{3} \mathrm{~d}^{-1}$ ). In Childs River our fresh SGD (2680 424 and $6159 \mathrm{~m}^{3} \mathrm{~d}^{-1}$ ) was very close to Cambareri and Eichner's (1998) estimate which is a 425 representative of a yearly average $\left(2740 \mathrm{~m}^{3} \mathrm{~d}^{-1}\right)$. Our results for fresh SGD for the whole 426 bay are lower than Cambareri and Eichner's (1998) and we believe that is because we 427 could not properly survey Quashnet River and hence our estimates are missing a 428 relatively large fresh SGD component. 
43008 (Fig. 7). In general, radon levels were elevated throughout the bay with several SGD

431 hot-spots indicated by high radon in the Inner Harbor and Quincy Bay (red circles on Fig.

432 7). In some parts of the harbor radon and salinity showed a strong negative correlation

433 suggesting the discharge of low salinity high radon groundwater (Inner Harbor), in the

434 southern part of our survey (Quincy Bay) the lack of negative correlation between

435 salinity and radon indicates the presence of mostly brackish/saline groundwater

436 discharge.

437 SGD rates varied from 1.5 to $10 \mathrm{~m}^{3} \mathrm{~m}^{-1} \mathrm{~d}^{-1}$. The highest fluxes occurred in the 438 northern sectors of the harbor. This survey covered approximately 50\% of the coastline

439 in North Harbor and 10\% in South Harbor. The corresponding SGD rates were 90x10

$440 \mathrm{~m}^{3} \mathrm{~d}^{-1}$ and $20 \times 10^{3} \mathrm{~m}^{3} \mathrm{~d}^{-1}$ in the surveyed sections. If extrapolated to represent discharge

441 from the total length of coastline would be 11 and 39\% of river discharge in the North

442 and South Harbors, respectively (http://waterdata.usgs.gov/nwis/rt). These fluxes include

443 the discharge of fresh and marine groundwater components. In comparison, total

444 groundwater discharge determined from an earlier study in Quincy Bay (Wollaston

445 Beach) ranged from 1.3 to $2.2 \times 10^{3} \mathrm{~m}^{3} \mathrm{~d}^{-1}$ on a coast-perpendicular transect that was

446 scaled up to represent a $4.6 \mathrm{~km}$ length of coastline. This flux was calculated to be

447 equivalent to 7-12\% of surface discharge (Poppe and Moffett, 1993). Our survey results

448 at the Wollaston Beach suggest rates from 1.4 to $2.2 \times 10^{3} \mathrm{~m}^{3} \mathrm{~d}^{-1}$ but our study also

449 indicates that SGD is variable and the rate doubles in the southeast section of the beach.

450 We expect that this spatial variability in SGD (Fig. 7) may explain the difference in 
451 calculated groundwater to surface discharge ratios (i.e., our 39\% estimate as opposed to

452 the 12\% estimated by Poppe and Moffett, 1993).

453 Fresh SGD calculated based on the National Urban Runoff Program model

454 (Menzie et al., 1991) for the whole South Harbor is $41 \times 10^{3} \mathrm{~m}^{3} \mathrm{~d}^{-1}$ and the North Harbor

455 is $43 \times 10^{3} \mathrm{~m}^{3} \mathrm{~d}^{-1}$, representing 8 and $3 \%$ of river discharge, respectively (Menzie et al.,

456 1991). These fluxes cannot be directly compared to our estimates because these are only

457 fresh groundwater discharge rates. Instead, we used these numbers to calculate the ratio

458 of fresh to total SGD from our survey. The modeled fresh SGD represents $23 \%$ of total

459 SGD in the North Harbor and 2\% in South Harbor. We acknowledge that we did not

460 survey Hingham Bay where we expect an increase in SGD due to the presence of

461 marshes that focus groundwater discharge and are sites of intense tidally induced

462 groundwater circulation. Our total SGD estimate for South Harbor based on the survey

463 in Quincy Harbor (only 10\% of total coastline length) is therefore probably

464 underestimated.

465

4664.3 Groundwater-derived nitrogen

$467 \quad$ Considering that groundwater nutrient concentrations are usually elevated in

468 comparison to surface water it is important to examine SGD as source of nitrogen to

469 coastal waters. Our survey provides indirect evidence of these sources based on the co-

470 occurrence of elevated levels of nitrogen species and SGD hot-spots. The method proves

471 to be effective in distinguishing groundwater nitrogen fluxes from inputs from surface

472 runoff or other sources, because only the groundwater nitrate/ammonia is accompanied

473 by radon. 
474 Simultaneous radon and dissolved inorganic nitrogen (DIN) measurements in the surface

475 water can be simplified to the following scenarios:

476 1) High radon - high DIN are an indication of significant SGD with possible

$477 \quad$ elevated groundwater nitrogen inputs;

478 2) High radon - low DIN* are an indication of significant SGD with insignificant $479 \quad$ nitrogen inputs;

480 3) Low radon - low DIN* are an indication of insignificant SGD and nitrogen inputs;

481 4) Low radon - high DIN are an indication of insignificant SGD and elevated

482 nitrogen inputs from sources other than groundwater, i.e. surface water runoff and $483 \quad$ precipitation.

484 *Because nitrogen species water column residence time is highly dependent on 485 seasonality (due to biological uptake), high surface water DIN can be observed before the 486 spring bloom starts when nitrogen is not consumed quickly, and preferably at or around 487 low tide when the groundwater signal is most evident. Therefore rather than comparing 488 absolute concentration differences in coastal waters between summer and winter seasons, 489 one should examine trends in DIN concentrations in correlation with SGD.

490 DIN concentration in Waquoit Bay was much higher in the winter than summer.

491 In the summer, nitrate (the only measured $\mathrm{N}$ species) concentrations correspond nicely to 492 variations in SGD throughout the bay (Fig. 8) and peak at $6 \mu \mathrm{M}$ in the Childs River 493 where total SGD rates also peak at $5.5 \mathrm{~m}^{3} \mathrm{~m}^{-1} \mathrm{~d}^{-1}$. Moderate groundwater fluxes in 494 Quashnet River $\left(2 \mathrm{~m}^{3} \mathrm{~m}^{-1} \mathrm{~d}^{-1}\right)$ are not accompanied by significant nitrate concentrations. 495 Winter nitrate concentrations are more evenly distributed with no apparent correlation 496 with SGD. This may be due to rapid biological nitrogen uptake in the summer when any 
497 new source would be apparent in excess of a low background concentration. In contrast

498 the winter nitrogen residence time in the surface water is much longer, allowing build-up

499 and more even distribution within the bay (Valiela et al., 1992). Another explanation is

500 that the nitrate+nitrite concentration is different in fresh and recirculated groundwater and

501 when the relative magnitude of fresh and recirulated groundwater discharge changes so

502 does the nitrate+nitrite concentration of the surface water (Kroeger and Charette, 2008).

503 To test the association of SGD and DIN inputs in detail, the two sites in Waquoit

504 Bay with the highest SGD rates (Childs River and Quashnet River) were continuously

505 monitored for radon, salinity and nutrients during a period of one low tide-high tide cycle

506 (Fig. 1 and Fig. 9). We found that in the Childs River radon activities (4-12 dpm L ${ }^{-1}$ )

507 were associated with elevated DIN and low salinity suggesting a fresh groundwater

508 source. This supports our findings from the survey that there is high SGD and

509 groundwater derived nitrate in the Childs River. Other nutrients such as phosphate and

510 silicate exhibited no clear association with radon or salinity so we could not conclude that

511 SGD is their primary source (Fig. 9). Ammonia was constant throughout the

512 measurement period at $\sim 5 \mu \mathrm{M}$. In contrast, in Quashnet River radon levels were

513 comparable to those in the Childs River but nitrate concentrations were negligible and

514 DIN consisted almost exclusively of ammonia. Ammonia was at the same level as in

515 Childs River (1-5 $\mu \mathrm{M})$. DIN was not correlated with radon and therefore its source could

516 not be SGD. Phosphate and silicate had the same decreasing trend as radon.

517 The differences between the two sites can be explained by land-use practices in

518 their watersheds as these influence groundwater composition. The Childs River

519 watershed is more urbanized with septic tanks and fertilizers as major nitrogen sources 
520 than the Quashnet River watershed. Valiela et al. (1992) found that these urbanized

521 watershed areas significantly influence groundwater DIN concentrations - most

522 significantly nitrate. Our results are in accordance with these findings.

523 Water quality in Boston Harbor improved after the Deer Island wastewater

524 treatment facility discharge was moved offshore in 2000 (Taylor, 2006). DIN

525 concentrations in the harbor dropped by $50 \%$ over the following five years. Currently, the

526 major sources of nitrogen into the harbor are atmospheric deposition, rivers, groundwater

527 discharge, stormwater discharge, combined sewer outflows, and coastal disposal sites

528 (Menzie et al., 1991, MWRA, 2008). During our survey ammonia concentrations ranged

529 from 1.6 to $41 \mu \mathrm{M}$ (median $20 \mu \mathrm{M}$ ) and nitrate+nitrite concentrations were an order of

530 magnitude lower, between 0.1 and $5.8 \mu \mathrm{M}$ (median $0.7 \mu \mathrm{M}$ ). Due to the complexity of

531 point and non-point nitrogen sources in the harbor no clear correlation between

532 ammonia/nitrate and radon can be expected for the harbor as a whole. Areas in Inner

533 Harbor, Dorchester Bay, and Quincy Bay show high SGD and surface water DIN (Fig. 7).

534 This implies that the source of these nutrients may be groundwater discharge. Sites with

535 moderate SGD rates (i.e. western Dorchester Bay) are also potential sources of

536 groundwater derived nitrogen. Sites that had elevated SGD but low DIN are SE Quincy

537 Bay and Pleasure Bay. At these sites groundwater is not a significant source of DIN into

538 the surface water, despite high discharge rates. These findings illustrate the high

539 variability of SGD in the harbor and its possible effects on surface water DIN

540 concentration. Sites with potential significant groundwater derived nitrogen that

541 necessitate further investigation are the Inner Harbor and parts of Dorchester Bay and

542 Quincy Bay. Although SGD is an obvious potential source of nutrients here, its 
543 significance may be diminished by point releases of effluents into surface waters

544 throughout the harbor (Fig. 1 based on http://www.mwra.state.ma.us/harbor/graphic/4-

545 1.gif).

547 4.4 Groundwater DIN fluxes

548 There is ongoing debate as to how best derive groundwater nutrient fluxes from

549 known groundwater discharge rates and groundwater nutrient concentration measured in

550 wells and piezometers. Valiela et al., (1992) illustrated that nitrogen attenuation by

551 denitrification, sorption of ammonia, and other microbial processes may decrease

552 nitrogen levels in groundwater along its flow path. Additional biochemical processes in

553 the subterranean estuary (Kroeger and Charette, 2008) and at the sediment water interface

554 (Seitzinger, 1988) further modify the groundwater composition and make it difficult to

555 estimate groundwater nitrogen concentrations at the point of discharge. A simple

556 multiplication of groundwater discharge and nutrient concentrations in the groundwater

557 therefore provide only a rough estimation of nutrient fluxes.

558 In Waquoit Bay groundwater DIN concentrations measured in coastal wells in the

559 Childs River watershed averaged $133 \mu \mathrm{M}$ and $4.2 \mu \mathrm{M}$ in the Quashnet River watershed

560 (Valiela et al., 1992), and at the head of the bay the best representative DIN values were

56194 and $27 \mu \mathrm{M}$ for fresh groundwater and recirculated seawater, respectively. The latter

562 values were derived by Kroeger and Charette (2008) from Jun, Jul 2002, Mar, Apr, Jun,

563 July 2003 and from a 3-year long monthly monitoring of the subterranean estuary at the

564 head of Waquoit Bay concurrent with our surveys (unpublished results). The simplistic

565 approach of multiplying these concentrations with groundwater fluxes from our survey, 
566 result in groundwater derived nitrogen fluxes of $68-87 \mathrm{~kg} \mathrm{~N} \mathrm{~d}^{-1}$ in the winter and 9.5-13

$567 \mathrm{~kg} \mathrm{~N} \mathrm{~d}^{-1}$ in the summer. Valiela et al. (1992) and Kroeger and Charette (2008) also

568 estimated that in Waquoit Bay approximately $60-75 \%$ of the DIN is removed within a

569 thin layer at the sediment-water interface, so the net fluxes may be as much as $60-75 \%$

570 lower than our estimates.

571 For the survey in Quincy Bay (South Boston Harbor) we can use nitrogen

572 concentrations measured by Poppe and Moffett (1993) who found DIN concentrations

573 ranging from $20 \mu \mathrm{M}$ (nearshore) to $140 \mu \mathrm{M}$ (50 m inland). They contend that nitrogen

574 concentrations decrease within their shallow coastal well transect due to denitrification.

575 Based on these concentrations we calculate DIN fluxes of 7-51 $\mathrm{kg} \mathrm{N} \mathrm{d}^{-1}$ for that part of

576 the harbor. North Harbor is even more complex as there are sites with elevated SGD but

577 low nitrogen and also sites with elevated nitrogen and SGD. This suggests that

578 groundwater DIN is highly variable. Menzie et al. (1991) determined representative

579 groundwater DIN concentrations throughout the harbor of 7 to $710 \mu \mathrm{M}$. Using their

580 average value of $71 \mu \mathrm{M}$ we get a DIN flux of $81 \mathrm{~kg} \mathrm{~N} \mathrm{~d}^{-1}$. But these results need further

581 improvement with more detailed groundwater DIN determination. Nevertheless our SGD

582 survey already provides reliable groundwater discharge rates and a good basis for future

583 groundwater DIN flux investigations.

584

585 5. Conclusions

586 By combining radon/methane/nitrate into a survey system we are able to quickly

587 and efficiently create detailed maps of submarine groundwater discharge in coastal

588 embayments. The new methane analyzer provided excellent resolution and response to 
589 varying methane concentrations in Waquoit Bay. The enhanced radon monitoring system

590 had improved resolution though use of the membrane contactor interface can become

591 clogged in high particulate environments. We developed a model for converting mapped

592 radon into total SGD fluxes in Waquoit Bay and Boston Harbor and determined areas of

593 significant groundwater fluxes. These data were combined with surface water nitrogen

594 concentrations to identify areas of potential non-point source pollution. Two sites in

595 Waquoit Bay were studied in detail for correlation between nitrate and radon over a tidal

596 cycle and the results confirmed that in Childs River there is high groundwater derived

597 nitrate, whereas Quashnet River has SGD which is not a considerable source of nitrate.

598 All of our results were in good agreement with earlier findings of SGD and the location

599 of nitrogen sources in Waquoit Bay.

600 We identified several sites in Boston Harbor that had significant SGD coincident

601 with elevated surface water nitrogen concentrations, but more detailed investigations are

602 needed to confirm SGD as a nitrogen source. However, our survey results provide basis

603 for further studies. We are confident that the survey system is very effective in revealing

604 areas of non-point source pollution and that this system is suitable for larger scale

605 regional SGD mapping projects.

606

607 Acknowledgements

608 The authors wish to thank the Waquoit Bay National Estuarine Research Reserve

609 for their continued support of our research efforts in Waquoit Bay and Francesco Peri and

610 the crew of the Landing craft from the Environmental, Earth \& Ocean Sciences

611 Department at the University of Massachusetts in Boston for their assistance with the 
612 survey of Boston Harbor. R. Camilli acknowledges the National Ocean Partnership

613 Program (NOPP) for supporting the development of the TETHYS mass spectrometer

614 through research grant \#OCE-0537173. H. Dulaiova, M. A. Charette and R. Camilli

615 acknowledge funding support from the WHOI Coastal Institute and MIT Sea Grant

616 College Program under NOAA grant number NA06OAR4170019, project number

617 5710002173. H. Dulaiova was funded by the WHOI Academic Program’s postdoctoral

618 scholarship.

619

620

621

622 


\section{References}

624 Bugna, G. C., J. P. Chanton, J. E. Cable, W. C. Burnett, and P. H. Cable, 1996. The

625 importance of groundwater discharge to the methane budgets of nearshore and

626 continental shelf waters of the northeastern Gulf of Mexico. Geochimica et

627 Cosmochimica Acta 60 (23): 4735-4746.

628 Burnett, W.C., J. P. Chanton, J. Christoff, E. Kontar, M. Lambert, W. S. Moore, D.

629 O’Rourke, C. Smith, L. Smith, and M. Taniguchi, 2002. Assessing methodologies for

630 measuring groundwater discharge to the ocean. EOS 83: 117-123.

631 Burnett, W. C., and H. Dulaiova, 2003. Estimating the dynamics of groundwater input

632 into the coastal zone via continuous radon-222 measurements. Journal of

633 Environmental Radioactivity 69: 21-35.

634 Burnett, W.C., P.K. Aggarwal, A. Aureli, H. Bokuniewicz, J.E. Cable, M.A. Charette, E.

635 Kontar, S. Krupa, K.M. Kulkarni, A. Loveless, W.S. Moore, J.A. Oberdorfer, J.

636 Oliveira, N. Ozyurt, P. Povinec, A.M.G. Privitera, R. Rajar, R.T. Ramessur, J.

637 Scholten, T. Stieglitz, M. Taniguchi, J.V. Turner, 2006. Quantifying submarine

638 groundwater discharge in the coastal zone via multiple methods. Science of the Total

$639 \quad$ Environment 367: 498-543

640 Cable, J.E. G. C. Bugna, W. C. Burnett, and J. P. Chanton, 1996. Application of ${ }^{222}$ Rn

641 and $\mathrm{CH}_{4}$ for assessment of groundwater discharge to the coastal ocean. Limnology \&

$642 \quad$ Oceanography 41: 1347-1353.

643 Cambareri, T. C., and E.M. Eichner. 1998. Watershed Delineation and Ground Water

644 Discharge to a Coastal Embayment. Ground Water 36: 626-634. 
645 Camilli, R., Duryea, A., 2007. Characterizing marine hydrocarbons with in-situ mass

646 spectrometry, IEEE/MTS OCEANS '07 On the Edge of Tomorrow Vancouver,

647 Canada, pp. 1-7.

648 Charette, M.A., K. O. Buesseler, and J. E. Andrews, 2001. Utility of radium isotopes for

649 evaluating the input and transport of groundwater-derived nitrogen to a Cape Cod

650 estuary. Limnology and Oceanography 46(2): 465-470.

651 Charette, M.A.,W.S. Moore and W.C. Burnett, 2008. Uranium- and thorium-series

652 nuclides as tracers of submarine groundwater discharge. Radioactivity in the

653 Environment, ed. S. Krishnaswami, J.K. Cochran, vol: "U-Th Series Nuclides in

654 Aquatic Systems" 13: 155-191.

655 Corbett, D. R., K. Dillon, W. C. Burnett, and J. P. Chanton, 2000. Estimating the

656 groundwater contribution into Florida Bay via natural tracers, ${ }^{222} \mathrm{Rn}$ and $\mathrm{CH}_{4}$.

657 Limnology \& Oceanography 45: 1546-1557

658 Dulaiova, H., R. Peterson, W. C. Burnett, and D. Lane-Smith. 2005. A multidetector

659 continuous monitor for assessment of ${ }^{222} \mathrm{Rn}$ in the coastal ocean. J. Radioan. and Nucl.

$660 \quad$ Chem. 263(25): 361-365.

661 Dulaiova W. C. Burnett, J. P. Chanton, W. S. Moore. H. J. Bokuniewicz, M. A. Charette,

662 and E. Sholkovitz, 2006. Assessment of groundwater discharge into West Neck Bay,

663 New York, via natural tracers. Continental Shelf Research 26(16): 1971-1983.

664 Dulaiova, H., Gonneea, M. E., P. B. Henderson, and M. A. Charette, 2008. Geochemical

665 and physical sources of radon variation in a subterranean estuary - Implications for 
666 radon groundwater end-member activities in submarine groundwater discharge studies, 667 Marine Chemistry 110(1-2): 120-127.

668 Eganhouse, R.P., Sherblom, P.M., 2001. Anthropogenic organic contaminants in the 669 effluent of a combined sewer overflow: impact on Boston Harbor. Marine $670 \quad$ Environmental Research 51, 51-74.

671 Jiang M. S. and M. Zhou, 2008. The Massachusetts Bay Hydrodynamic Model: 2005

672 Simulation. Boston: Massachusetts Water Resources Authority. Report 2008-12. 58 673 pp.

674 Kim, G. and D.-W. Hwang, 2002. Tidal pumping of groundwater into the coastal ocean 675 revealed from submarine ${ }^{222} \mathrm{Rn}$ and $\mathrm{CH}_{4}$ monitoring. Geophysical Research Letters 29 $676 \quad$ (14): 23-27.

677 Lee, Y.-W. and G. Kim, 2007. Linking groundwater-borne nutrients and dinoflagellate 678 red-tide outbreaks in the southern sea of Korea using a Ra tracer. Estuarine, Coastal $679 \quad$ and Shelf Science, 71(1-2), 309-317

680 Kroeger, K.D., and M.A. Charette, 2008. Nitrogen biogeochemistry of submarine 681 groundwater discharge. Limnology and Oceanography 53: 1025-1039.

682 Mau, S., Valentine, D.L., Clark, J.F., Reed, J., Camilli, R., Washburn, L., 2007.

683 Dissolved methane distributions and air-sea flux in the plume of a massive seep field, 684 Coal Oil Point, California. Geophysical Research Letters 34.

685 McGroddy, S. E., and J.W. Farrington, 1995. Sediment porewater partitioning of 686 polycyclic aromatic hydrocarbons in three cores from Boston Harbor, Massachusetts. 687 Environmental Science \& Technology, 29: 1542-1550. 
688 Menzie, C. A., J. J. Cura, J. S. Freshman, and B. Potocki, 1991. Boston Harbor: Estimates

689 of loadings. Report 91-4, Massachusetts Water Resources Authority, Harbor Studies

$690 \quad$ Group. pp. 122.

691 Michael, H. A. 2004. Seasonal dynamics in coastal aquifers: investigation of submarine

692 groundwater discharge through field measurements and numerical models. $\mathrm{PhD}$

693 dissertation, MIT.

694 Michael, H. A., Lubetsky, J. S., Harvey, C. F., 2003. Characterizing submarine

695 groundwater discharge: a seepage meter study in Waquoit Bay, Massachusetts.

696 Geophysical Research Letters 30. Doi:10.1029/2002GL0160000.

697 Michael, H. A., A. E. Mulligan, and C. F. Harvey, 2005. Seasonal oscillations in water

698 exchange between aquifers and the coastal ocean. Nature 436(7054): 77-87.

699 Moore, W. S., 1996. Large groundwater inputs to coastal waters revealed by ${ }^{226} \mathrm{Ra}$

$700 \quad$ enrichments. Nature 380: 612-614.

701 Mulligan, A. E. and M. A. Charette, 2006. Intercomparison of submarine groundwater

702 discharge estimates from a sandy unconfined aquifer. Journal of Hydrology, 327: 411-

$703 \quad 425$.

704 MWRA, 2008, The state of Boston harbor. The harbor and river monitoring program:

$705 \quad$ http://www.mwra.state.ma.us/harbor/html/bhmonitoring.htm

706 Poppe, L. J. and A. M. Moffett, 1993. Ground water discharge and the related nutrient 707 and trace metal fluxes into Quincy Bay, Massachusetts. Environmental Monitoring

708 and Assessment, 25: 15-27. 
709 Robinson, C., B. Gibbes, and L. Li, 2003. Driving mechanisms for groundwater flow and

710 salt transport in a subterranean estuary, Geophysical research letters, 33, L03402,

711 doi:10.1029/2005GL025247.

712 Seitzinger, S. P., 1988. Denitrification in freshwater and coastal marine ecosystems:

713 Ecological and geochemical significance. Limnology and Oceanography 33: 702-724.

714 Slomp, C. P. and P. Van Cappellen, 2004. Nutrient inputs to the coastal ocean through

715 submarine groundwater discharge: controls and potential impact. Journal of

$716 \quad$ Hydrology 295: 64-86.

717 Stolzenbach, K. D., and E.E. Adams, 1998. Contaminated sediments in Boston Harbor.

718 Cambridge, MA: MIT Sea Grant College Program.

719 Sumner, D. M. and G. Belaineh, 2005. Evaporation, precipitation and associated salinity

720 changes at a humid, subtropical estuary. Estuaries, 28(6), 844-855.

721 Taylor D. I., 2006. 5 years after transfer of Deer Island flows offshore: an update of

722 water-quality improvements in Boston Harbor. Boston: Massachusetts Water

723 Resources Authority. Report ENQUAD 2006-16. 77 p.

724 Umezawa Y., I. Herzfeld, C. Colgrove, and C.M. Smith, 2008. Impact of terrestrial

725 nutrients through submarine groundwater discharge (SGD) on macroalgal bloom at

726 fringing reef ecosystem "(In) From Headwaters to the Ocean: Hydrological Change

727 and Watershed Management,” M. Taniguchi, Y. Fukushima, W.C. Burnett, M. Haigh

728 and Y. Umezawa, Eds. Rotterdam, Balkema. 
729 Valiela, I., J. Costa, K. Foreman, J. M. Teal, B. Howes, D. Aubrey, 1990. Transport of

730 groundwater-borne nutrients from watersheds and their effects on coastal waters.

$731 \quad$ Biogeochemistry 10: 177-197.

732 Valiela I., K. Foreman, M. LaMontagne, D. Hersh, J. Costa, P. Peckol, B. DeMeo-

733 Andreson, C. D'Avanzo, M. Babione, C.-H. Sham, J. Brawley, K. Lajtha, 1992.

734 Couplings of watersheds and coastal waters- sources and consequences of nutrient

735 enrichment in Waquoit Bay, Massachusetts, Estuaries 15(4): 443-457. 

for the whole bay estimated in previous studies and in this study in August 2006 and December 2006.

\begin{tabular}{|c|c|c|c|c|c|c|c|c|}
\hline & \multicolumn{3}{|c|}{ Head of bay } & \multicolumn{2}{|c|}{ Childs River } & \multicolumn{3}{|c|}{ Whole bay } \\
\hline $\operatorname{SGD}\left(\mathrm{m}^{3} \mathrm{~d}^{-1}\right)$ & Fresh & Saline & Total & Fresh Saline & Total & Fresh & Saline & Total \\
\hline Cambareri and Eichner (1998) & 1,037 & & & 2,740 & & 27,648 & & \\
\hline Michael et al. (2003) & 950 & & 9,160 & & & & & \\
\hline Michael (2004) & 2,160 & 4,234 & 6,394 & & & & & \\
\hline Mulligan and Charette (2006) & 2,419 & & & & & & & \\
\hline Charette et al. (2001) & & & & & & & 37,152 & \\
\hline This study Aug06 & 2,050 & & 2,845 & 2,680 & 6,880 & 5,367 & & 11,212 \\
\hline This study Dec06 & 920 & & 4,292 & 6,159 & 51,587 & 7,588 & & 56,862 \\
\hline
\end{tabular}


Figure captions:

740 Fig. 1 A: Map of Massachusetts with insets of B: Waquoit Bay, the crosses indicate the

741 Childs River and Quashnet River time series monitoring sites; C: Boston Harbor with

742 its bays, the cross indicates the Savin Hill Cove time series measurement site, also

743 indicated are North Harbor and South Harbor.

744 Fig. 2: Response time of Liquicel and the air-water gas exchanger to changes in radon

745 activities in water. First, radon-free water was passing through both systems, after 20

746 minutes the water intake was switched to high radon activity water, and after 55

747 minutes the water intake was switched back to radon-free water. Ten minutes after

748 switching from high radon to radon-free water intake $10 \%$ of the radon remains in

749 the Liquicel system. The same $10 \%$ level is reached in the air-water gas exchanger

$750 \quad$ after $\mathbf{4 5}$ minutes.

751 Fig. 3 A: Radon measured during a survey in Waquoit Bay, MA with two different radon

752 mapping systems, one system used a classic air-water exchanger and the other the

753 newly tested membrane. Both systems were run in 5 minute integrated intervals and

754 their water intakes were positioned to sample the same water parcel. For easier

755 comparison, radon values are plotted against time instead of geographical reference

756 points. B: Simultaneous radon and methane survey in Waquoit Bay, MA. Radon is

757 smoothed out spatially because it has been measured in a continuous 5-minute

758 integrated measurement intervals, whereas methane values were recorded every 30

759 seconds. Values are plotted against time of sample collection.

760 Fig. 4: Sources and removal processes that influence radon/methane inventory in the

761 coastal water. The input terms are indicated by brown arrows and loss terms by green

762 arrows, and the tracer fluxes represent the interactions between sediments, coastal

763 water, atmosphere, and offshore water.

764 Fig. 5: Long-term monitoring of radon, water level, and salinity in Savin Hill Cove in

765 Boston Harbor. The inset is zoomed in on a selected time period that shows a clear

766 negative correlation between salinity/tides and radon. At high tide the water is

767 diluted by low radon high salinity offshore water, at low tides fresh/brackish SGD 
lowers salinity and brings in new radon that is then mixed away with the next flood tide.

770 Fig. 6: Summer (A, B, C) and winter (D, E, F, G) coastal surface water survey results


$\mu \mathrm{M}(\mathrm{C}, \mathrm{F})$; and methane in relative units (G, winter only). Warm colors are high and cold colors are low values as indicated on each legend. Due to low water levels we were not able to survey Quashnet River in such detail as the other parts of the bay.

Fig. 7: Coastal surface water survey results from Boston Harbor showing A: salinity; B:

Fig. 8: Nitrate+nitrite concentrations in surface water and radon derived SGD in Waquoit Bay in A: Aug 2006 and B: Dec 2006. In the summer, nitrate concentrations are very radon in dpm $\mathrm{L}^{-1}$; C: submarine groundwater discharge in $\mathrm{m}^{3} \mathrm{~m}^{-1} \mathrm{~d}^{-1}$; and D: ammonia + nitrate + nitrite in $\mu \mathrm{M}$. well correlated with SGD throughout the bay and peak at $6 \mathrm{mM}$ in the Childs River. Winter concentrations are more evenly distributed, exhibiting no apparent correlation with SGD. This may be due to a quick biological nitrogen uptake in summer when any new source would be apparent over a low background concentration, whereas in winter nitrogen residence time in the surface water is much longer allowing build-up and more even distribution within the bay (Valiela et al., 1992). Values are plotted against time of sample collection. 


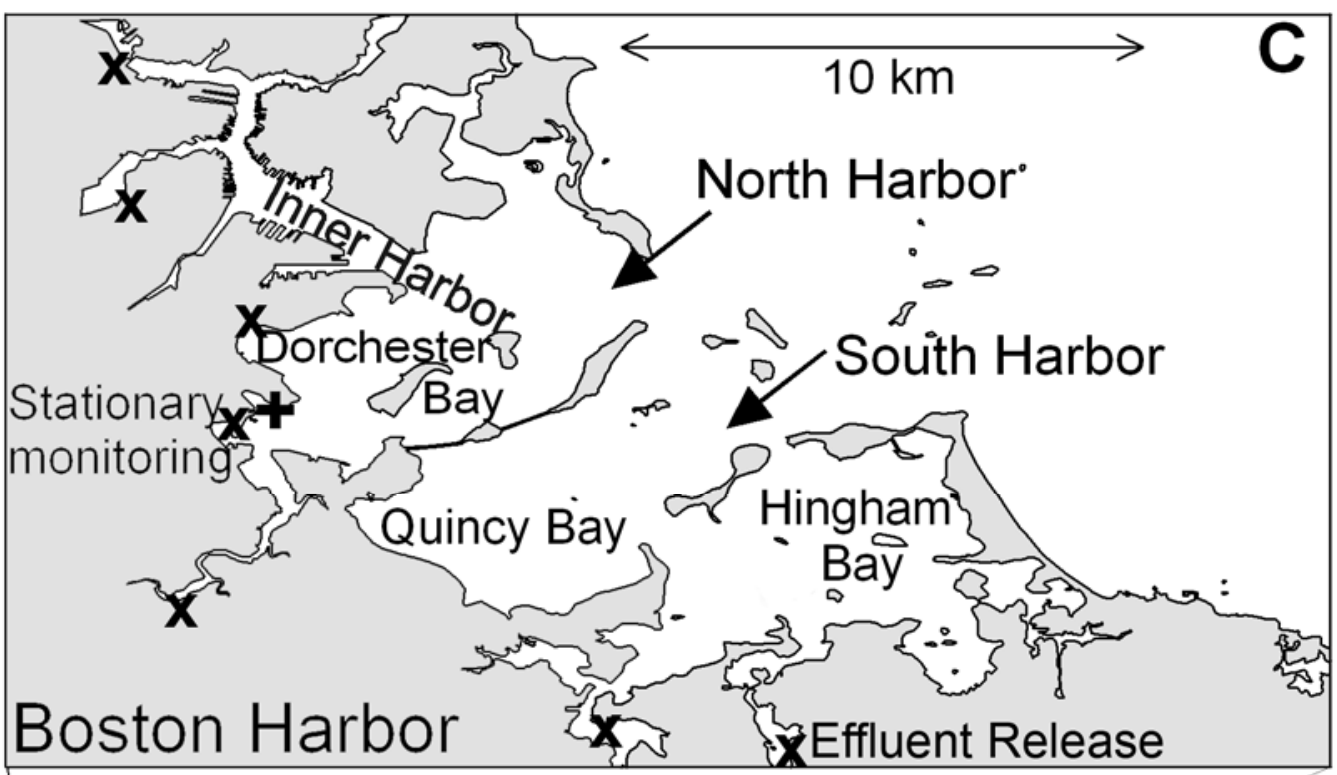

797

798 


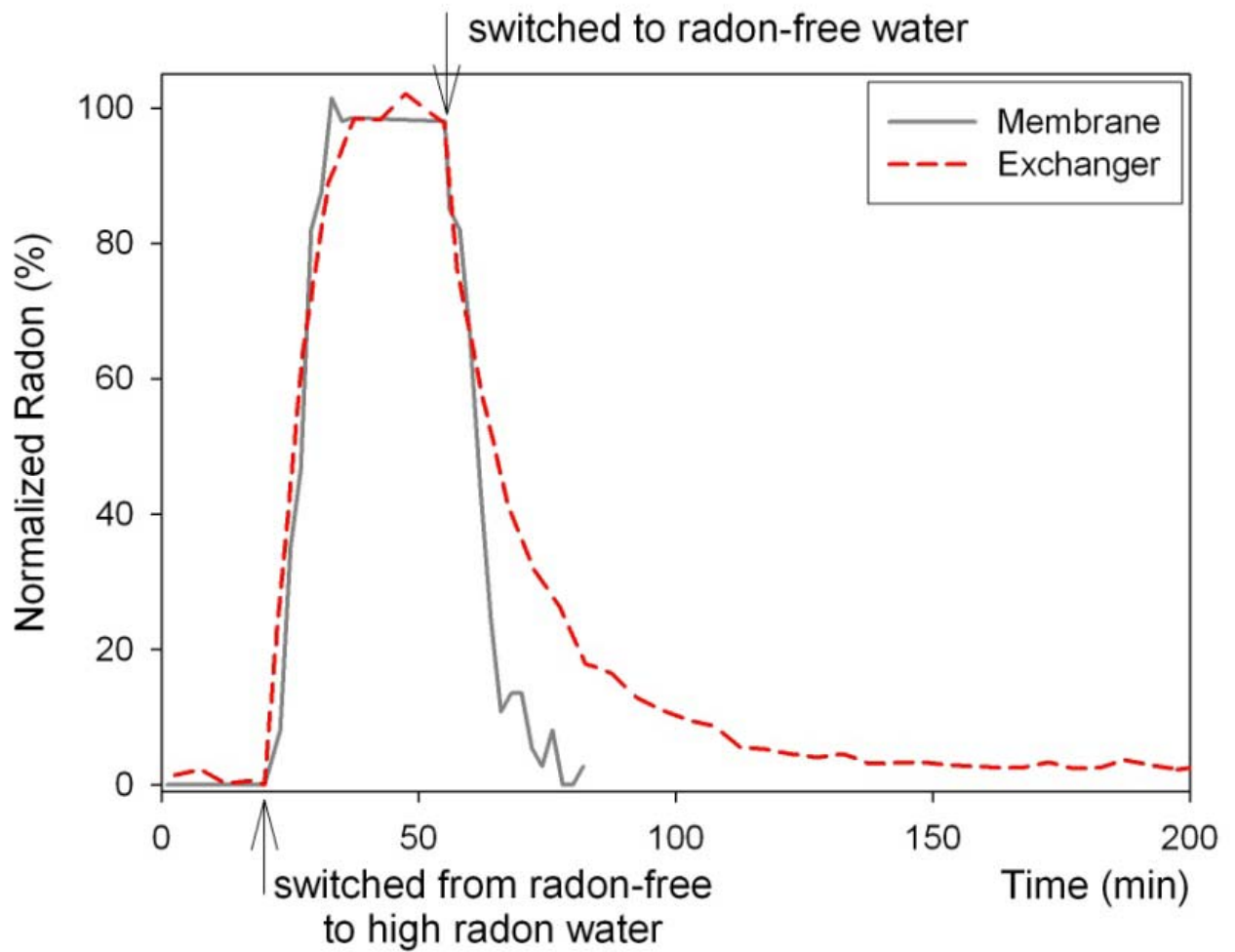

801

802

803

804

Fig. 2 
806


807

808

809

810

Fig. 3 


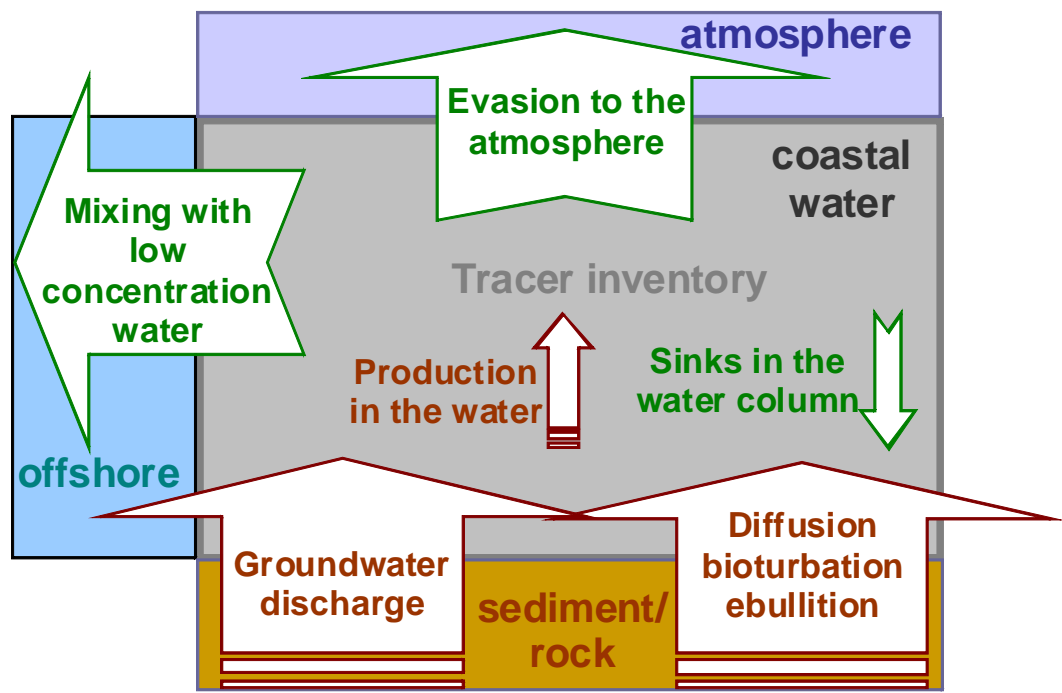

813

814

815

Fig. 4

816 


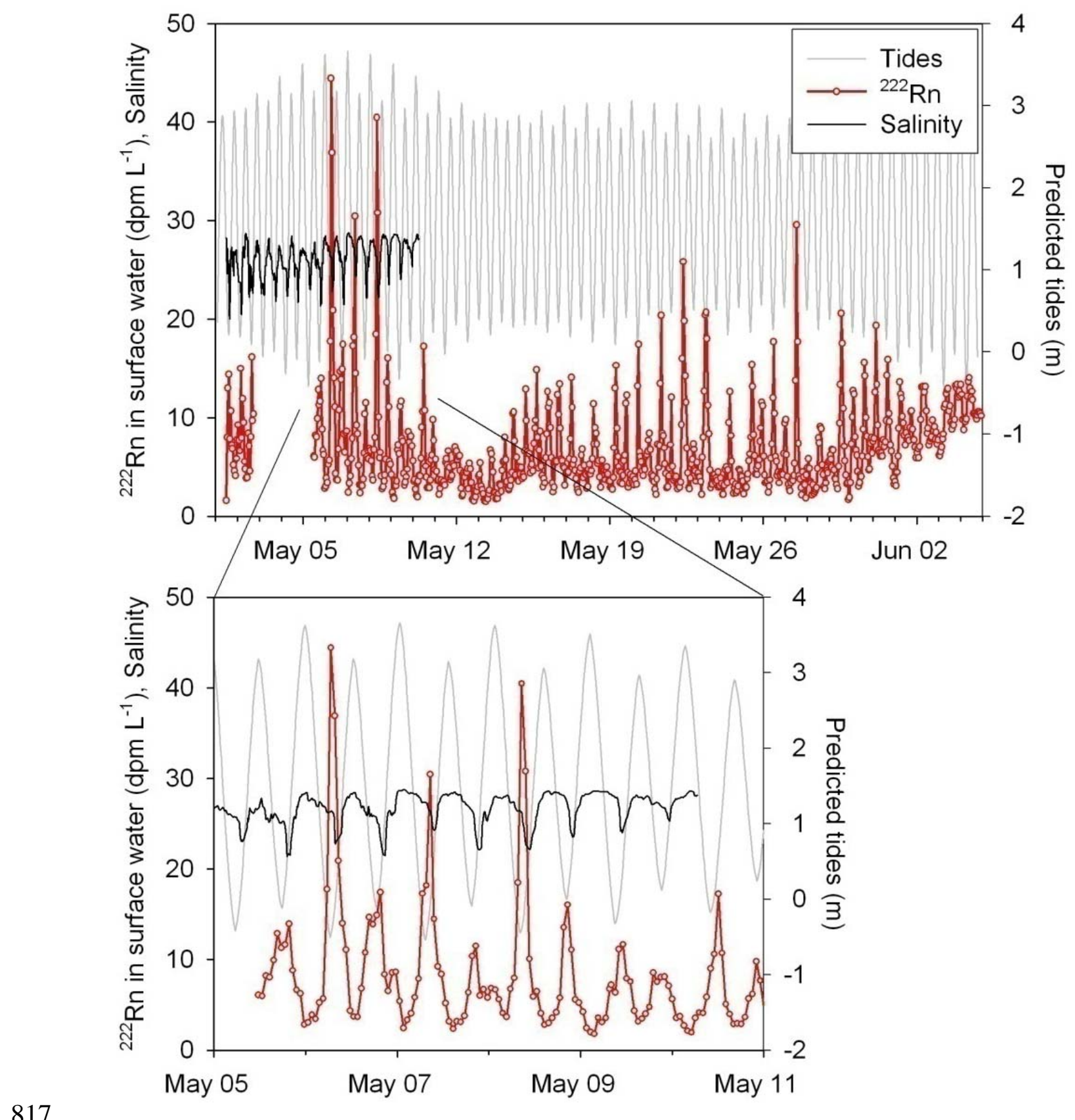

817

818

819

Fig. 5 

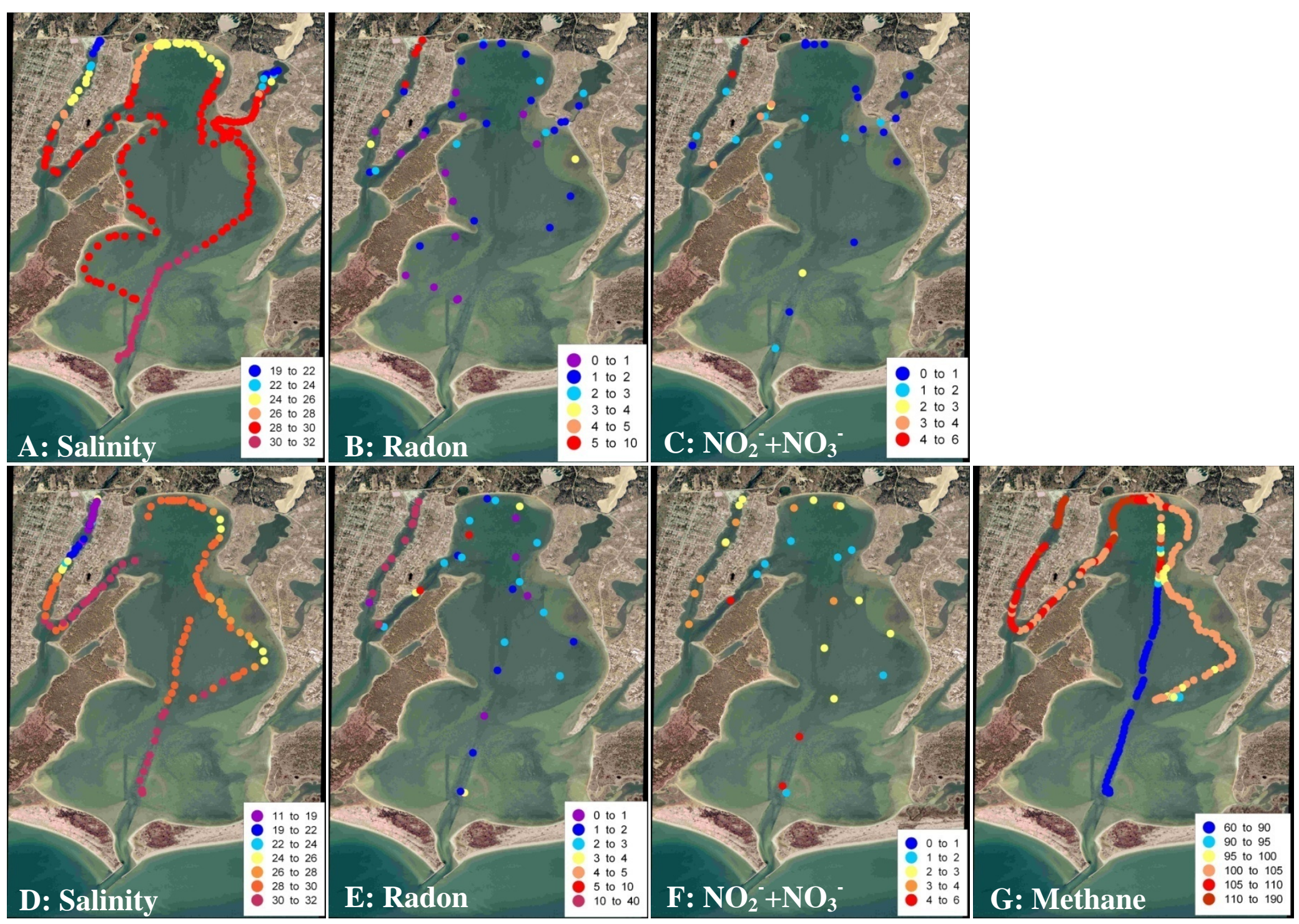

Fig. 6 






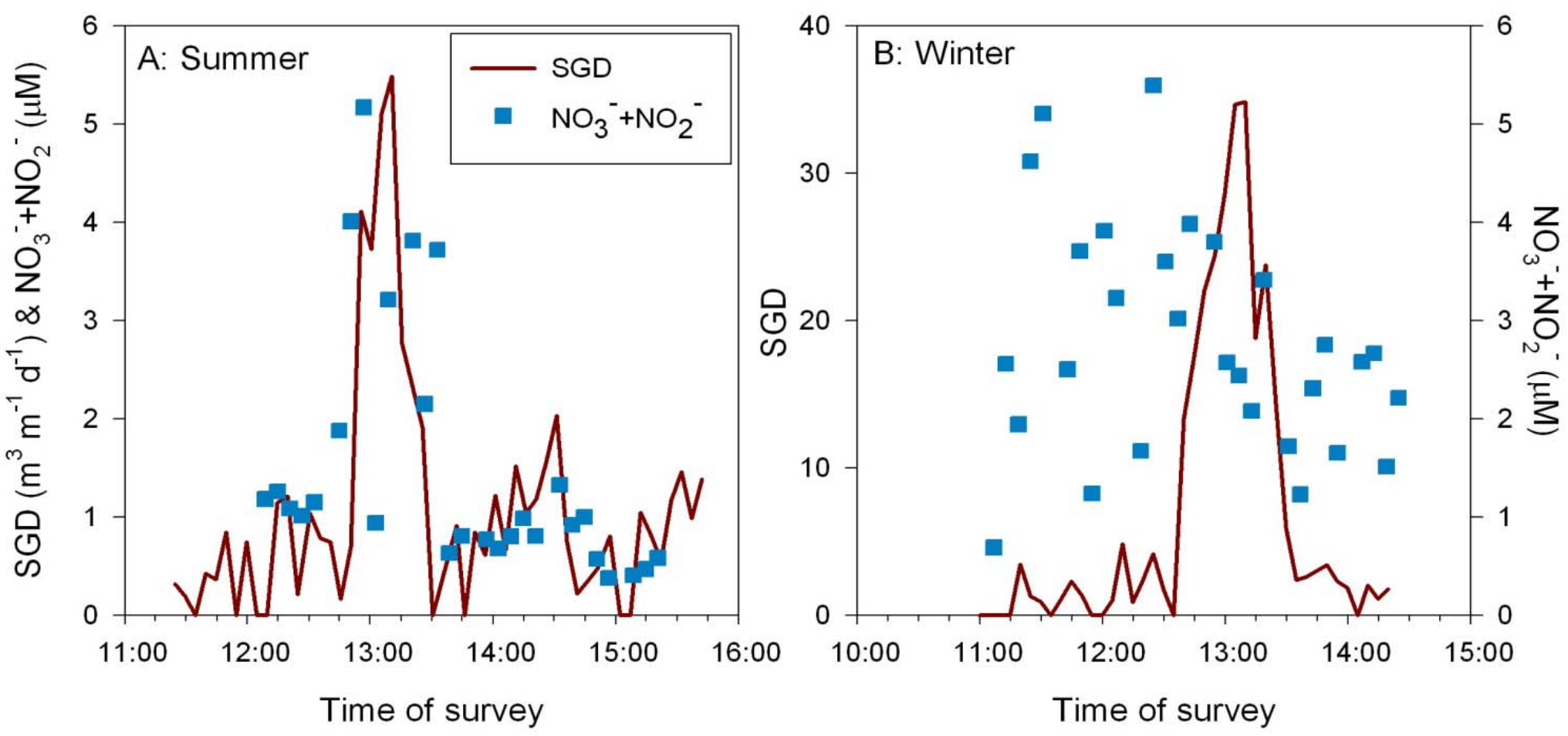

Fig. 8 
Childs River

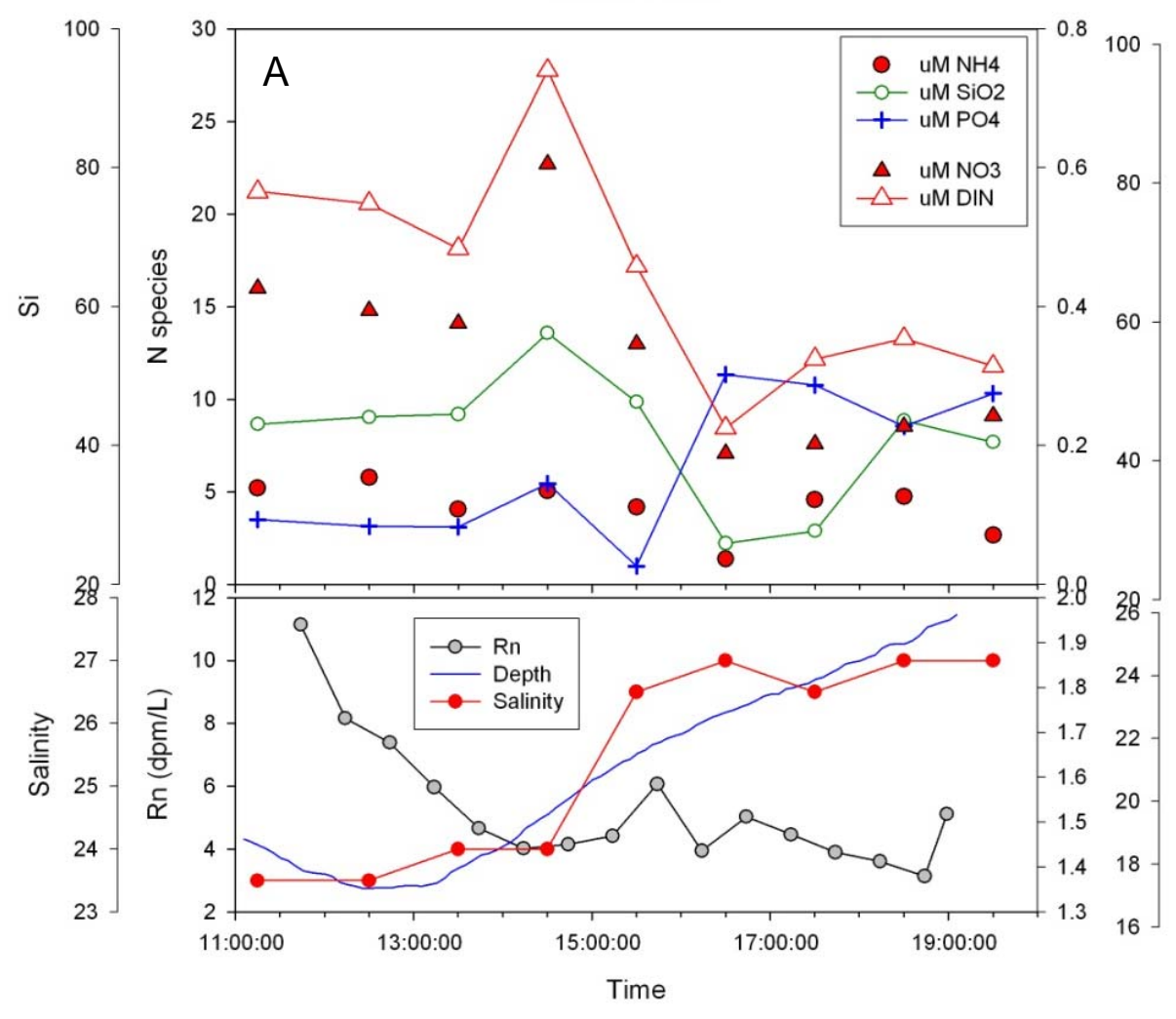

Quashnet River

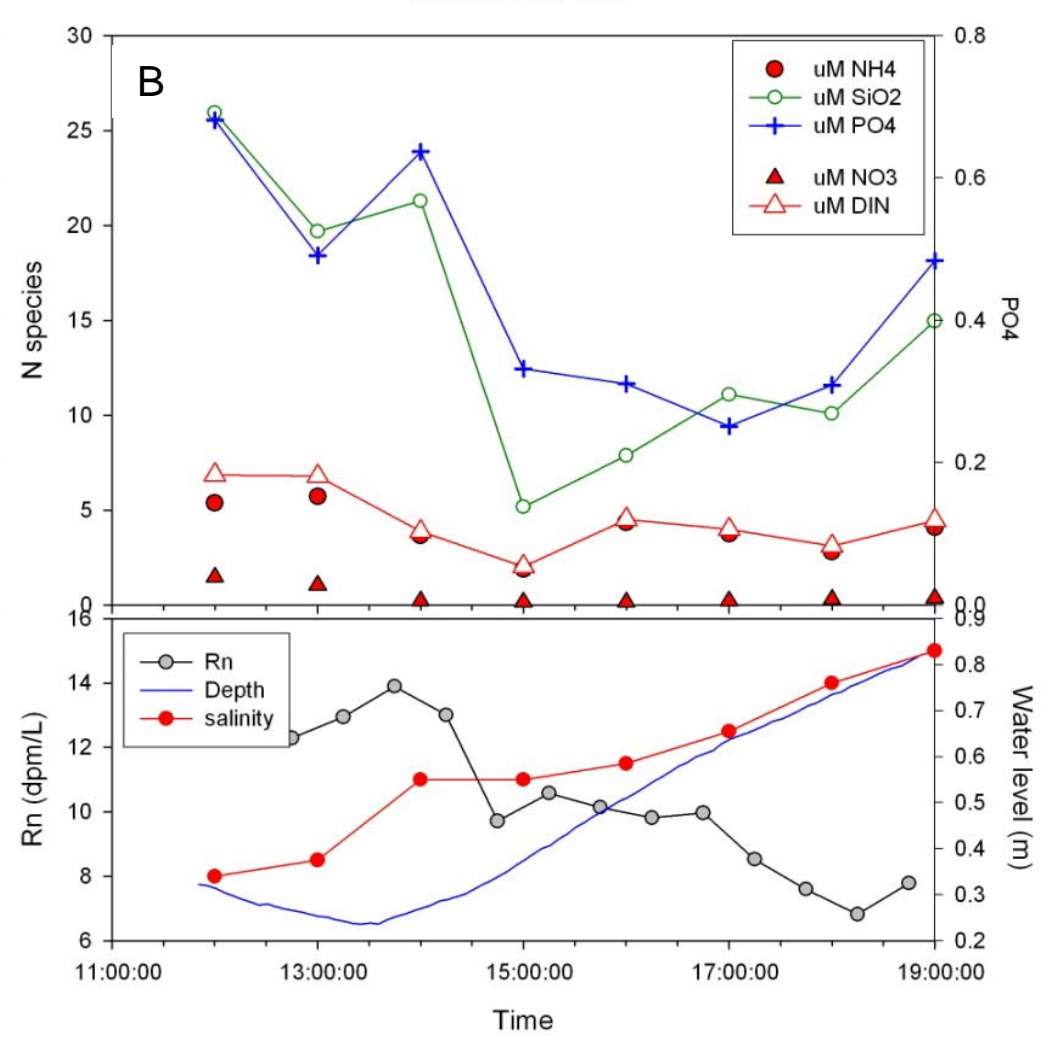

Fig. 9 